\title{
Earned Value Management System in Indonesian Construction Projects
}

\author{
Mandiyo Priyo ${ }^{1^{*}}$ \\ ${ }^{1}$ Department of Civil Engineering, Faculty of Engineering, \\ Universitas Muhammadiyah Yogyakarta, Kasihan, Bantul, 55183, INDONESIA \\ *Corresponding Author
}

DOI: https://doi.org/10.30880/ijie.2021.13.03.005

Received 22 September 2020; Accepted 09 March 2021; Available online 01 June 2021

\begin{abstract}
Earned Value Management (EVM) is a methodology combining scope, schedule, and resource measurements to assess project performance and progress. It involves integrating the three critical elements of the project covering schedule, work scope, and cost. Various benefits are associated with the use of EVM in project management. This research aims to analyze four units of building construction projects using the EVM method consisting of an analysis of project performance, estimation of cost, and time for project completion, and planning estimation analysis against project completion. The results revealed that from the aspect of time, three buildings were completed ahead of schedule, and another one was behind schedule. In terms of cost, three buildings cost lower than the estimated budget, while one other building was higher.
\end{abstract}

Keywords: Earned value management, construction, project management

\section{Introduction}

Project Management Institute [1] defines Earned Value Management (EVM) as "a methodology combining scope, schedule, and resource measurements to assess project performance and progress". Similarly, Vanhoucke [2] describe EVM as a Project Performance Measurement (PPM) method involving the integration of the three key elements of the project comprising scheduled, work scope, and cost. The author claims that the work of scope is indirectly related to EVM as the adequately completed work packages means that the work scope has been performed successfully.

Naderpour \& Dissanayake [3], [4] specify EVM as a recognized system providing quantitative measures to project performance and integrating it with cost and schedule. Likewise, De Marco and Narbaev [5] assert, "a method of thoroughly quantifying the technical performance of the project and integrating it with cost and time is earned value management."

Vanhoucke [2] suggests three critical parameters of EVM required to measure project performance comprising Planned Value (PV), Actual Cost (AC), and Earned Value (EV). Chou \& Chen [6] states that the critical parameters of EVM should be in the same unit. It can be measured in either dollar (\$) or work hour (time).

In conclusion, many researchers have defined EVM in the same way, using different terms and expressions having the same meaning. It is because the significant EVM dimensions are cost, schedule, and work scope combined to assist the project team in successfully managing the project performance.

EVM is a useful technique extensively used by project managers to monitor project performance, concerning scope, cost, and schedule, throughout the implementation of a project. Moreover, this technique serves as a forecasting mechanism indicating the expected project results. It allows project managers to adjust project strategy, make trade-offs based on the project objective, and adapt to the project environment [7], [8]. 
Earned Value Management System (EVMS) has recently kept cropping up in news articles. One of the primary reasons is that more and more government contracts are now demanding EVM reports. Many government contractors are project-oriented. Hence, government agencies are demanding on EVMS. EVMS is a methodology to help projects come to successful completion, whether in construction industries, information technology, or software development. EVM is considered as one of the most powerful and productive concepts utilized in managing today's complex projects in private, commercial, or government environments. It can combine measurements of scope, schedule, and costs. In short, it is a single integrated system.

EVM can provide accurate forecasts of project performance problems, which are an essential contribution to project management. EV analysis is a performance measurement method utilizing "work in progress" to indicate what will happen to work in the future. EV is an enhancement over traditional accounting progress measures. Traditional methods focus on planned accomplishment (expenditure) and actual costs. EV goes one step further and examines actual accomplishment. It provides managers greater insight into potential risk areas with a clear picture. EVNS is not a specific system or toolset, but rather, a set of guidelines guiding a company's management control system. EVM allows us to integrate project scope, schedule, and cost objectives against a baseline plan to accomplish project objectives. The popularity of EVM has grown significantly in recent years because it helps in substantiates contract disputes.

This paper aims to evaluate four units of building construction projects in Indonesia using EVMS comprising an analysis of project performance, estimates of cost and time for project completion, and analysis of planning estimation against project completion.

\section{Literature Review}

\subsection{Key Parameters of Earned Value Management System}

Earned Value Management (EVM) introduces several key parameter terms such as Budgeted Cost of Work Scheduled (BCWS) or Planned Value (PV), Budgeted Cost of Work Performed (BCWP), or Earned Value (EV) and Actual Cost of Work Performed (ACWP) or Actual Cost (AC). Key parameters of EVMS are shown in Fig. 1, Fig. 2 and Fig. 3.

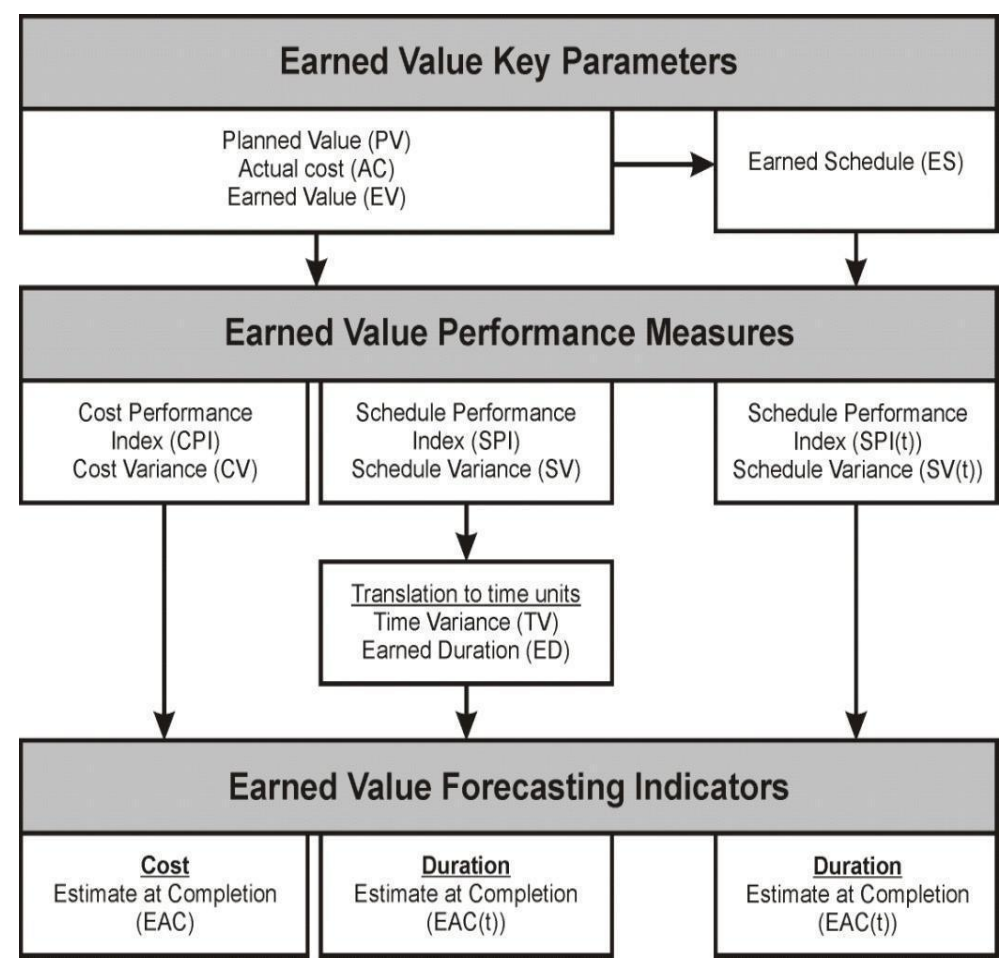

Fig. 1 - Key Parameters of EVMS [8]

The above key parameters are defined below:

- $\quad$ Budgeted Cost of Work Scheduled (BCWS) or Planned Value (PV) - The sum of budgets for all work packages scheduled to be accomplished within a given period.

- $\quad$ Budgeted Cost of Work Performed (BCWP) or Earned Value (EV) - The sum of budgets for completed work packages and completed portions of open work packages. 
- Actual Cost of Work Performed (ACWP) or Actual Cost (AC) - The actual cost incurred in accomplishing the work performed within a given period.

- Performance Measurement Baseline (PMB) - The sum of all work packages of BCWS for each period, calculated for the EV analysis for the total project duration. The PMB forms the time-phased budget plan against which project performance is measured.

- Performance Measurement Baseline (PMB) - The sum of all work packages of BCWS for each period, calculated for the EV analysis for the total project duration. The PMB forms the time-phased budget plan against which project performance is measured.

- Schedule Variance (SV) - The difference between the work performed (BCWP) and the work scheduled (BCWS). The schedule variance is calculated on the difference of dollar value between the amount of work to complete in a given period and the work completed.

- Cost Variance (CV) - The difference between the planned cost of work performed (BCWP) and the actual cost incurred for the work (ACWP). The actual dollar value by which a project is either overrunning or under running its estimated cost.

- Cost Variance (CV) - The difference between the planned cost of work performed (BCWP) and the actual cost incurred for the work (ACWP). The actual dollar value by which a project is either overrunning or under running its estimated cost.

- Cost Variance (CV) - The difference between the planned cost of work performed (BCWP) and the actual cost incurred for the work (ACWP). The actual dollar value by which a project is either overrunning or under running its estimated cost.

- Estimate at Completion (EAC) - It is a forecast of most likely total project costs based on project performance and risk quantification. At the beginning of the project, BAC and $\mathrm{EAC}$ are equal. EAC will vary from BAC only when actual costs (ACWP) vary from the planned costs (BCWP).

- Estimate to Complete (ETC) - The difference between EAC and AC. It is the estimated additional cost to complete the project at any given time.

- Variance at Completion (VAC) - The difference between BAC and EAC. It is the dollar value by which the project will be over or under budget.

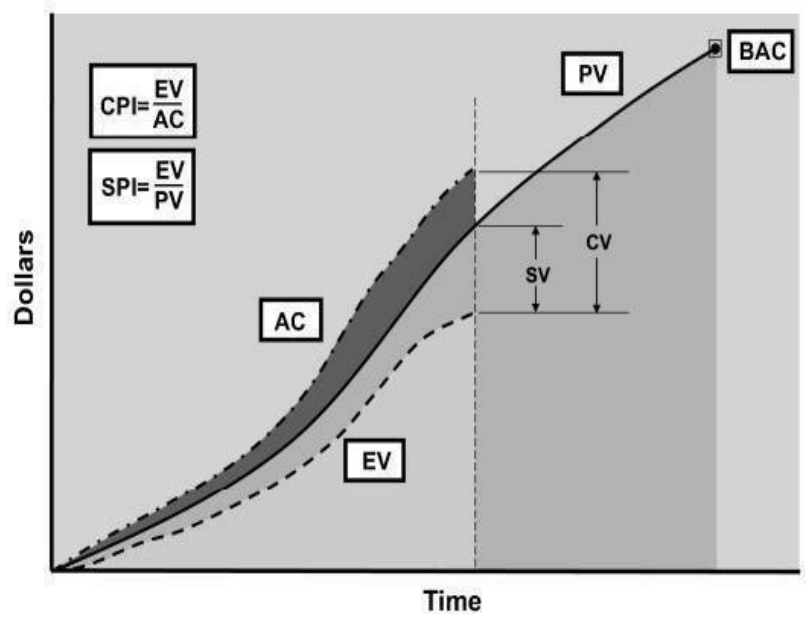

Fig. 2 - Earned Value Basics [8]

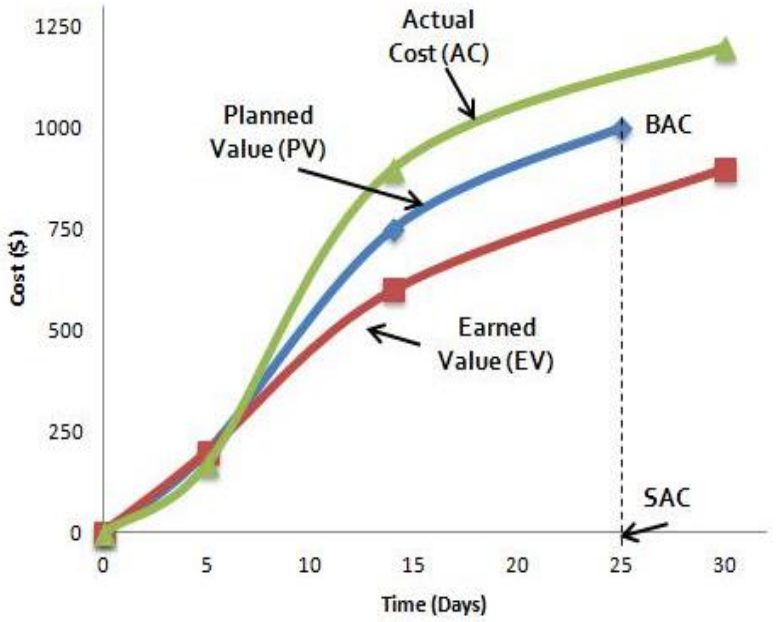

Fig. 3 - Earned Value of Main Components [ 8 ]

\subsection{Earned Value Performance Measures}

The performance indicators used in the EV method provide the PM with a notion of how the project performs regarding duration and costs. Performance indicators give the PM an early warning signal to know that corrective actions should be implemented. These indicators and the calculations are depicted in Table 1.

- Schedule Performance Index (SPI): comparing the EV and the PV at a given period of a project.

- Cost Performance Index (CPI): comparing the EV and the AC at a specific project period.

- Schedule Variance (SV): contrasting the EV and the cost of work scheduled to be performed to date (PV).

- Cost Variance (CV): contrasting the amount of money budgeted for the work performed up to date (EV) and the actual cost of executing that work (AC).

- Time Variance (TV): defining the amount of time the project is ahead or behind by translating the SV to time units. 
Table 1 - Summary of Earned Value Performance Measure Calculations

\begin{tabular}{ccc}
\hline $\begin{array}{c}\text { Performance } \\
\text { Measure }\end{array}$ & Notation & Formula \\
\hline $\begin{array}{c}\text { Earned Value } \\
\text { Schedule }\end{array}$ & EV & $\begin{array}{c}\text { PV *\%Work } \\
\text { Complete }\end{array}$ \\
$\begin{array}{c}\text { Performance Index } \\
\text { Cost Performance } \\
\text { Index }\end{array}$ & SPI & EV / PV \\
$\begin{array}{c}\text { Schedule Variance } \\
\text { Cost Variance }\end{array}$ & SV & EV / AC \\
$\begin{array}{c}\text { Time Variance } \\
\text { Estimated at } \\
\text { Completion } \\
\text { Estimated to } \\
\text { Complete }\end{array}$ & TV & EV - AC \\
Variation at & EAC & EAC / CPI \\
Completion & VAC & EAC - AC \\
Time Estimate at \\
Completion
\end{tabular}

\subsection{Earned Value Forecasting Indicators}

Forecasting indicators predict the project's time and cost at completion based on actual performance achieved up to a specific time. These indicators are presented in Table 1, including the calculations. Fig. 4(a) visually shows CV, SV and TV for the same project used to generate Fig. 1. Fig. 4(b) illustrates the calculation of the ETC, EAC, and VAC forecasting indicators.

- Estimated at Completion (EAC): also refers to as Cost Estimated at Completion (CEAC), indicating the cost at which the project will be completed based on the current performance of the project.

- Estimated to Complete (ETC): estimating the cost required to complete the project from the evaluated instance forward.

- Variation at Completion (VAC): indicating the variation between the original budget at completion and the new predicted cost to complete the project.

- Time Estimate at Completion (TEAC): forecasting the time at which the project will be completed, given the unintentional changes produced to the initial plan.

- Time Variance at Completion (TVAC): indicating the amount of time the project is completed ahead of or behind schedule.
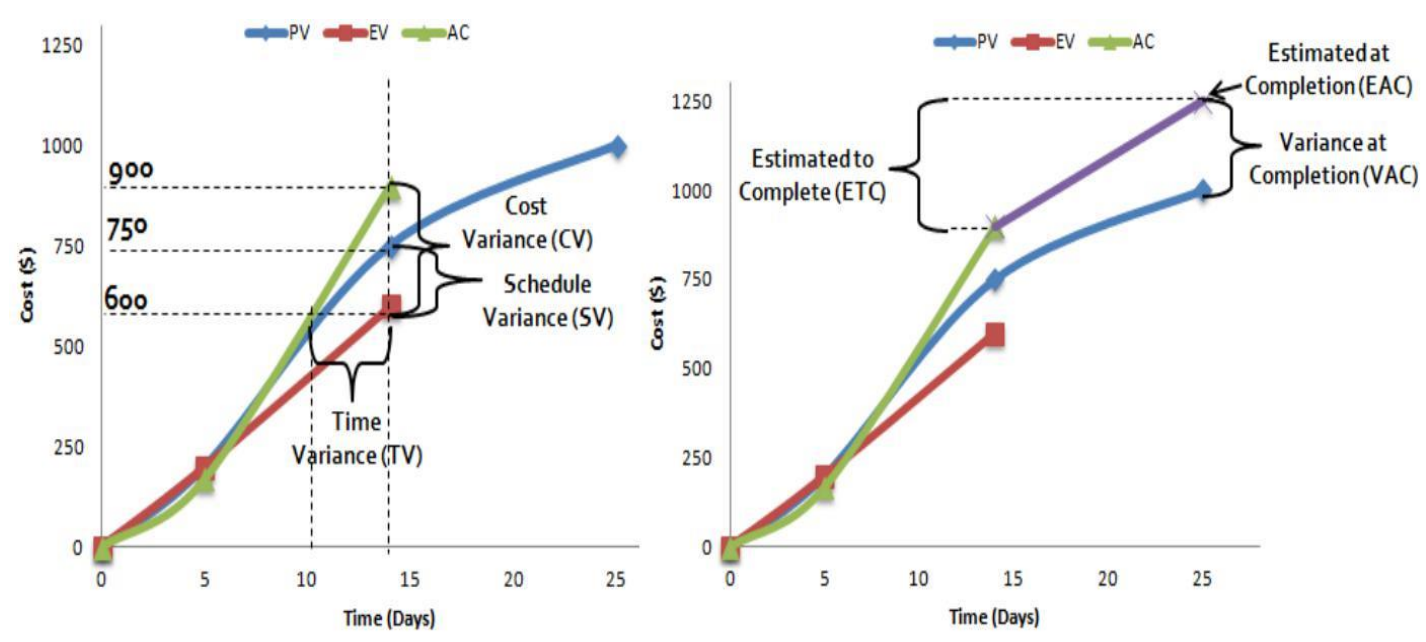

Fig. 4 - (a) Earned Value Variances, and (b) Earned Value Forecasting Indicators [8] 


\section{Study Methodology}

The research was implemented in four units of building construction projects in Indonesia. Two buildings are hospitals, one building is an official residence and one building is an office. The four projects are scattered in different location. The review was conducted every week. The performance measurement of cost and time at project execution employed the concept of Earned Value (EV) analysis. Furthermore, a live interview was conducted with the contractors to identify the factors affecting project performance and other supporting data. The project data required for this study consisted of primary and secondary data. The primary data were interview results with the selected respondent from the contractors regarding factors affecting project performance. The secondary data consisted of schedule, budget estimates, progress reports, and actual cost. This study utilized EV analysis comprising an analysis of project performance, estimates of cost and time for project completion, and analysis of planning estimation against project completion or To Complete Performance Index (TCTP).

\section{Results}

This paper aims to evaluate four units of building construction projects in Indonesia using the EVMS which consists of project performance analysis, project cost and time estimation, and project planning forecast analysis. The results of analysis of EV indicators, variance, project performance, time and cost estimates, and project plans for project completion, Building Project A on week 12, Building Project B on week 19, Building Project C on week 16, Building Project D at week 28 will be described as follows.

\subsection{Building Project A}

The analysis results of EV indicators, variance, project performance, time and cost estimation, and project planned against project completion at week 12 are displayed in Table 2.

Table 2 - Result Recapitulation of Earned Value Analysis at Week 12

\begin{tabular}{crl}
\hline $\begin{array}{c}\text { Earned Value } \\
\text { Parameter }\end{array}$ & \multicolumn{1}{c}{ Value } & \multicolumn{1}{c}{ Information } \\
\hline BAC (IDR) & $6,775,453,636.36$ & Contract value \\
PV (IDR) & $1,661,494,640.88$ & \\
EV (IDR) & $3,927,338,878.24$ & \\
AC (IDR) & $2,992,077,000.00$ & \\
\hline SV (IDR) & $2,265,844,237.36$ & Project reached in week 12 faster \\
CV (IDR) & $936,261,878.24$ & The cost in week 12 is cheaper than BAC \\
CPI & 1.313 & The cost in week 12 is cheaper than BAC \\
SPI & 2.364 & Project is faster \\
EAC (IDR) & $5,839,191,758.12$ & \\
ETC (IDR) & $2,848,114,758.12$ & \\
TE & 13 & \\
TCPI & 1,000 & Project performance is stable \\
\hline
\end{tabular}

The explanation of Table 2 is provided as follows:

- The EV indicators at week 12 show the PV value of 1,661,494,640.88; the EV value of 3,927,338,878.24, and the AC value of 2,992,077,000.

- The SV value of 2,265,844,237.36 and the CV value of 936,261,878.24 indicated that the project was completed ahead of schedule and spent under budget.

- The SPI value of 2.364 and the CPI value of 1.313 implied that the project execution time was faster than the schedule and spent less budget.

- $\quad$ The $\mathrm{EAC}=5,839,191,758.12$, while the $\mathrm{ETC}=2,848,114,758.12$.

\subsection{Building Project B}

The analysis results of EV indicators, variance, project performance, time and cost estimation, and project planned against project completion at week 19 are presented in Table 3. 
Table 3 - Result Recapitulation of Earned Value Analysis at Week 19

\begin{tabular}{ccl}
\hline $\begin{array}{c}\text { Earned Value } \\
\text { Parameter }\end{array}$ & Value & \multicolumn{1}{c}{ Information } \\
\hline BAC (IDR) & $4,950,908,465.70$ & Contract value \\
PV (IDR) & $3,981,025,497.26$ & \\
EV (IDR) & $4,835,552,298$ & \\
AC (IDR) & $3,409,775,000$ & \\
SV (IDR) & $854,526,800.74$ & The project is completed faster than the schedule \\
CV (IDR) & $1,425,777,298.00$ & The cost is smaller than BAC \\
CPI & 1.418 & The cost is smaller than BAC \\
SPI & 1.215 & The project is completed faster than the schedule \\
EAC (IDR) & $3,525,131,167.70$ & \\
ETC (IDR) & $115,356,167.70$ & \\
TE & 21 & \\
TCPI (IDR) & 1,000 & The project performance is stable \\
\hline
\end{tabular}

The explanation of Table 3 is as follows:

- The EV indicators for week 19 display the PV value of 3,981,025,497.26, the EV value of 4,835,552,298, and the AC value of $3,409,775,000$.

- The SV value of $854,526,800.74$ and the CV value of $1,425,777,298$ signified that the project was completed faster than the schedule, and the cost spent was smaller than the budget.

- The values of SPI $=1.215$ and CPI $=1.418$ indicated that the time of project execution was ahead of schedule, and the cost was smaller than the budget.

- $\quad \mathrm{EAC}=3,525,131,167.70$ and $\mathrm{ETC}=115,356,167.70$

\subsection{Building Project C}

The analysis results of EV indicator, variance, project performance, time and cost estimation, and project planned against project completion at week 16 are presented in Table 4.

Table 4 - The Result Recapitulation of Earned Value Analysis at Week 16

\begin{tabular}{ccl}
$\begin{array}{c}\text { Earned Value } \\
\text { Parameter }\end{array}$ & Value & \multicolumn{1}{c}{ Information } \\
\hline BAC (IDR) & $1,065,000,000$ & Contract Value \\
PV (IDR) & $999,523,800$ & \\
EV (IDR) & $749,717,400$ & \\
AC (IDR) & $929,771,117$ & \\
\hline SV (days) & -27.99164642 & The project is late \\
CV (IDR) & $-11,711,341$ & The final cost is higher than BAC \\
CPI & 0.806346193 & The final cost is higher than BAC \\
SPI & 0.75007459 & The project is late \\
EAC (IDR) & $1,245,053,717$ & \\
ETC (IDR) & $315,282,600$ & \\
TE & 20 & \\
TCPI & 1,000 & Project performance is stable \\
\hline
\end{tabular}

The following description explains about Table 4:

- The indicators of EV at week 16 presents the PV value of 999,523,800, the EV value of 749,717,400, and the AC value of $929,771,117$.

- $\quad$ Project performance at week 16 shows a negative SV value of $-15,240,150$ and a positive SPI value of 0.75007459 $<1$. It indicated delays in project execution. In contrast, the value of CV was 11,711,341, and the value of CPI was $0.806346193<1$, meaning that the cost spent was higher than the estimated budget.

- The estimated cost of the project completion shows EAC $=1,245,053,717$, and ETC $=315,282,600$.

- The estimated project completion time required was 140 working days or 20 weeks.

- $\quad$ TCPI $=1$ means the project performance was stable. 


\subsection{Building Project D}

The analysis results of EV indicators, variance, project performance, time and cost estimation, and project planned against project completion at week 28 are displayed in Table 5.

Table 5 - Recapitulation of earned value analysis results at week 28

\begin{tabular}{ccl}
\hline $\begin{array}{c}\text { Earned Value } \\
\text { Parameter }\end{array}$ & Value & \multicolumn{1}{c}{ Information } \\
\hline BAC (IDR) & $\begin{array}{c}10,879,019,215.36 \\
\text { PV (IDR) }\end{array}$ & Contract Value \\
EV (IDR) & $9,334,696,697.06$ & \\
AC (IDR) & $7,147,160,380.83$ & \\
SV (IDR) & $-78,827,148.63$ & The project is late \\
CV (IDR) & $2,108,709,167.60$ & The final cost is lower than the BAC \\
CPI & 1.30 & The final cost is lower than BAC \\
SPI & 0.99 & The project is late \\
EAC (IDR) & $8,400,517,607.93$ & \\
ETC (IDR) & $1,253,357,227.10$ & \\
TE & 38 & \\
TCPI & 1.30 & Decreased performance \\
\hline
\end{tabular}

The explanation of Table 5 is presented as follows:

- The indicators of EV at week 28 illustrates the PF value of 9,334,696,697.06, the EV value of 9,255,869,548.43, and the AC value of 7,147,160,380.83.

- The project performance at week 28 is represented by the negative value of SV $(-78,827,148.63)$, and the SPI value of $0.99<1$, meaning that the project was completed before the schedule. Conversely, the value of CV was positive $(2,108,709,167.60)$, and the value of CPI was $1.30>1$, indicating that the actual cost was smaller than the budget.

- The total estimated cost to complete the project was EAC $(8,400,517,607.93)$ and ETC $(1,253,357,227.10)$. The estimated time to complete the project was 38 workdays. TCPI $>1$ or equal to 1.30 indicated a decrease in performance.

Fig. 5 shows the comparison of time and cost performance of the four building projects (Project A, Project B, Project $\mathrm{C}$ and Project D). Based on the figure. it can be seen that Building Project A has the highest Schedule Performance Index (SPI). This shows that Building Project A has the best performance in terms of time compared to other projects and the worst is Building Project C.

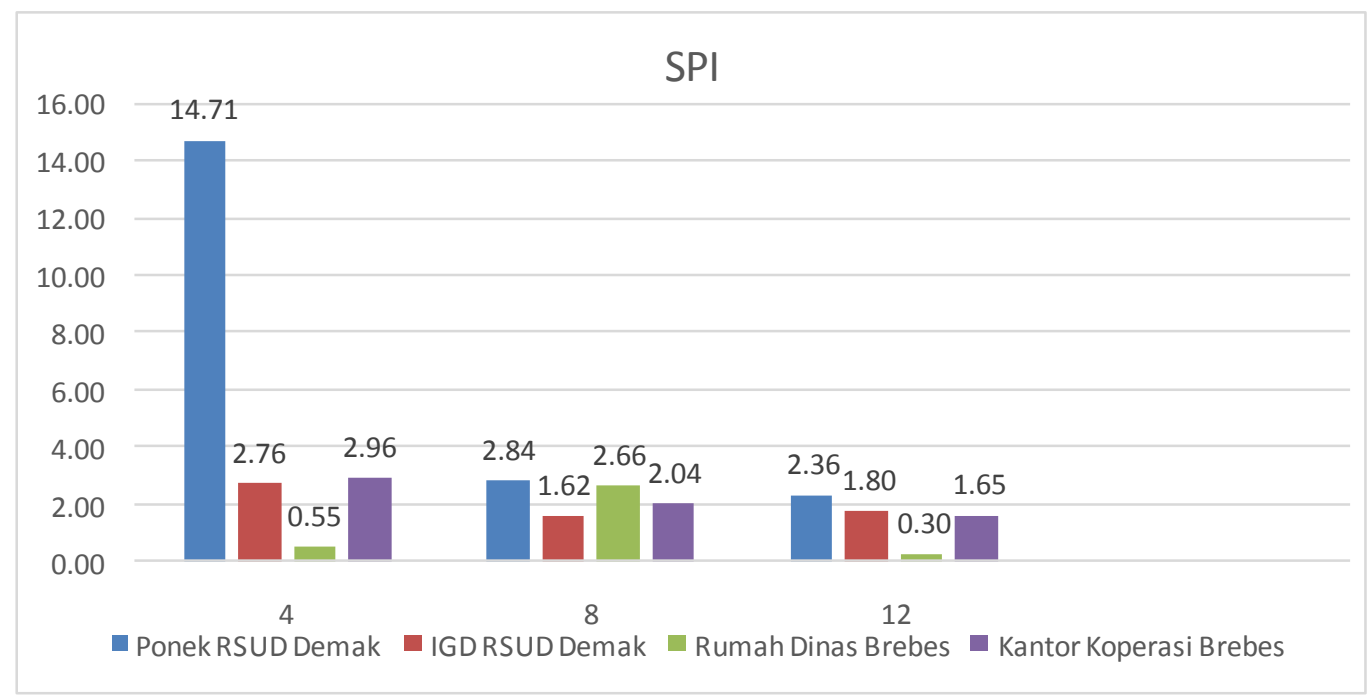

Fig. 5 - The Comparison of SPI value for four units of building projects at week 4, 8, and 12 


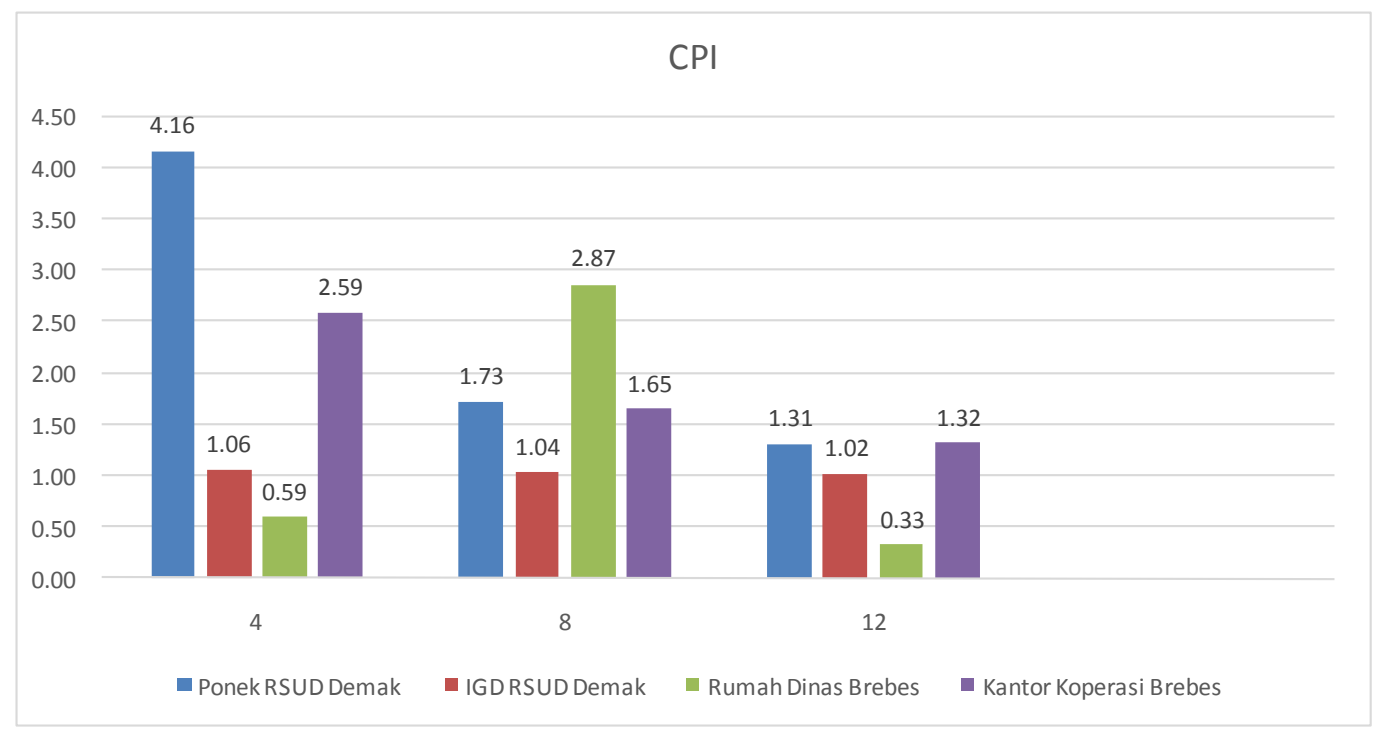

Fig. 6 - The Comparison of CPI value on Four Building Units in the Evaluation of Week 4, 8, and 12

Based on Fig. 6, it can be seen that Building Project A has the highest Cost Performance Index (CPI). This shows that Building Project A has the best performance in terms of cost compared to other projects and the worst is Building Project B.

\section{Discussion}

The Earned Value (EV) analysis results on four projects revealed that one project was completed behind schedule, and others were ahead of schedule. Furthermore, one project spent a higher cost than the estimated budget. EV analysis is a better program/project management method because it integrates cost, schedule, and scope and can be used to forecast future performance and project completion dates. It is an "early warning" program/project management tool enabling managers to identify and control problems before becoming insurmountable, allowing projects to be better managed on time and within budget.

It is observed that the implementation of EVMS in construction makes more viable and effective. It helps managers in making evidence-based decision about project scope, resources, and cost in overall project oversight. As a competitive purpose, the strategic management needs for enhancing cost and schedule control capabilities under globalized competition require to furnish EVMS techniques. The main contribution of the EVMS process was the motivation of the project manager and his staff concerning the cost management and the goal to finish the project on budget. The EVMS process provided more perception about the costs and their related elements of scope, contracts, performance, suppliers, risks, procurement, communications, quality, people and negotiations. EVMS inspires the participants to pay more attention to costs and progress, motivates the participants to discuss the cost elements with more intensity and optimize the costs resulting in a project that was finished on time and on budget.

\section{Conclusions}

The following conclusions were drawn based on the analysis results:

- Building Project A at week 12: (a) The value of PV was 1,661,341,231.64 IDR; the value of EV was 3,927,338,878.24 IDR, and the value of AC was 2,991,077,000 IDR. (b) The values of SV and CV indicated that the project was completed on time and under cost. Moreover, the value of SPI and CPI showed that the time of project execution was faster than the schedule and the cost spent was higher than the estimated budget. (c) The EAC value was 5,839,191,758.12 IDR, and the ETC value was 2,848,114,758.12 IDR, and the estimated time of project completion was 13 weeks. (d) When compared between the budget for additional workers' needs and the budget for overtime hours, it will be economical to choose the additional overtime hours.

- Building Project B at week 19: (a) The value of PV was 3,981,025,497.26 IDR, the value of AC was 3,409,775,000 IDR. (b) The values of SV and CV implied that the project was completed on time, and the actual cost was under the estimated budget. Moreover, based on the values of SPI and CPI, the execution time was faster than the schedule, and the cost spent was under the estimated budget. (c) The value of EAC was 3,525,131,167.70 IDR, and the value of ETC was 115,356,167.70 IDR, and the estimated time of project completion was 21 weeks. (d) If the budget of the addition of workers' needs and the budget for overtime hours are compared, it will be economical to select the additional workers. 
- Building Project $C$ at week 16: (a) The value of PV was 999,523,800 IDR, the value of EV was 755,379,050 IDR, and the value of AC was 929,771,117 IDR. The values of SV and CV revealed that the project was completed behind schedule, and the actual cost was higher than the estimated budget. Moreover, the values of SPI and CPI indicated that the project execution time was completed behind schedule, and the actual cost was higher than the estimated budget. (c) The value of EAC was 1,245,053,717 IDR, and the value of ETC was 315,282,600 IDR with an estimated completion duration of 20 weeks. (d) If the budget of additional workers' needs and overtime hours are compared, it will be better to add workers.

- Building Project D at week 28: (a) The value of PV was 9,334,696,697.06 IDR, the value of EV was 9,255,869,548.43 IDR, and the value of AC was 7,147,160,380.83 IDR. (b) The SV and CV values showed that the project was completed on time, and the actual cost was under the estimated budget. Furthermore, the SPI and CPI values signified that the project execution time was behind schedule, and the cost spent was under the estimated budget. (c) The value of EAC was 8,400,517,607.93 IDR, and the value of ETC was 1,253,357,227.10 IDR, with the estimated the budget for additional workers' needs and overtime hours.

- In a nutshell, the EV analysis on these four building projects disclosed that only one project was completed behind schedule, and others were on time. Moreover, only one project has an actual cost higher than the estimated budget. completion duration of 38 weeks. (d) Choosing the additional workers will be a better choice if comparing

\section{References}

[1] PMI (2013). A Guide to the Project Management Body of Knowledge (PMBOK@Guide). Project Management Institute

[2] Vanhoucke M. (2012). Project Management with Dynamic Scheduling. Earned Value Management. Berlin Heidelberg: Springer-Verlag. pp.215-238

[3] Naderpour A. \& Mofid M. (2011). Improving construction management of an educational centre by applying earned value technique. Procedia Engineering, 14, 1945-1952

[4] Dissanayake P. (2010). The earned value management system as a project management tool for the major multidisciplinary project. International Conference on Sustainable Built Environment, Kandy, pp. 14-21

[5] De Marco A. \& Narbaev T. (2013). Earned value-based performance monitoring of facility construction projects. Journal of Facilities Management, 11(1), 69-80

[6] Chou J. S., Chen H. M., Hou C. C. \& Lin C. W. (2010). Visualized EVM system for assessing project performance. Automation in Construction, 19(5), 596-607

[7] Bhosekar S. K. \& Vyas G. (2012). Cost is controlling using earned value analysis in construction industries. International Journal of Engineering and Innovative Technology, 1(4), 324-332

[8] Gupta R. (2014). Earned value management system. International Journal of Emerging Engineering Research and Technology, 2(4), 160-165 